\title{
Cobiprostone Spray
}

National Cancer Institute

\section{Source}

National Cancer Institute. Cobiprostone Spray. NCI Thesaurus. Code C124660.

A topical spray formulation containing the prostone cobiprostone, a type 2 chloride channel (CIC-2) agonist, with potential mucosal protective and anti-mucositis activities. Upon administration of cobiprostine via a spray into the oral cavity, cobiprostone specifically binds to and activates the CIC2 channel located on the mucosal membrane. This activates the epithelial CIC2 channel, enhances secretion of chloride, and promotes epithelial barrier repair. This prevents or reduces mucosal injury and reduces mucositis. $\mathrm{CIC2}$ plays a key role in the protection of mucosal barrier function. 